\title{
Las prestaciones económicas en los servicios sociales comunitarios de Andalucía. Análisis y reflexiones en torno al modelo actual
}

\author{
Javier Pacheco-Mangas \\ Servicios Sociales Comunitarios, Ayuntamiento de Vélez-Málaga (Málaga) \\ <http://orcid.org/0000-0002-5058-1427> \\ $<$ jpacheco@velezmalaga.es>
}

\section{Arantxa Hernández-Echegaray}

Servicios Sociales Básicos, Ayuntamiento de Palencia

<http://orcid.org/0000-0003-2553-7026>

\begin{abstract}
Gizarte-zerbitzu komunitarioak sarbide gertatzen dira gure herrialdeko gizarte-zerbitzu publikoen modu desberdinetara (oinarrizkoak, orokorrak, lehen mailako arreta-zerbitzuak). Berauek duten gertutasunak errazten du herritarren bizi-kalitatea hobetzea, eta errentaren birbanaketarako rol garrantzitsu bat betetzen dute. Artikulu honen asmoa da gizarte-zerbitzu komunitarioaren kudeaketaren eskumen diren edota tokiko eremuak erabateko garrantzia duen prestazio ekonomikoen azterketa deskriptibo bat burutzea. Andaluziako autonomia-erkidegoan zentratzen da, eta modu zehatzago batean Velez-Malagako Udaletxean (Malaga). Bertan buruturiko azterketak eztabaidarako gai batzuk azaltzen ditu, eta horien artetik nabarmentzen da aktoreen aniztasuna, bazterkeriaren inguruko egoera berriak aztertzearen premia, eta babes juridikoan eta bideratutako aurrekontuetan egin beharrezko hobekuntzak kontuan edukitzea.
\end{abstract}

\section{GAKO-HITZAK:}

Gizarte-zerbitzu komunitarioak, prestazio ekonomikoak, azterketa, gutxiengo errentak, gizarte-bazterketa.
Los servicios sociales comunitarios constituyen, en sus distintas denominaciones (básicos, generales, de atención primaria), la puerta de entrada a los sistemas públicos de servicios sociales en nuestro país. Su cercanía con la realidad facilita la influencia en la mejora de la calidad de vida de la ciudadanía, con un importante papel redistribuidor de renta. El presente artículo quiere trazar un análisis descriptivo de las prestaciones económicas que se encuentran bajo la gestión de los servicios sociales comunitarios o donde el papel del ámbito local es determinante. Centrado en la comunidad autónoma de Andalucía y, con carácter específico, en el Ayuntamiento de Vélez-Málaga (Málaga), el análisis realizado plantea elementos para la discusión, entre los que destacan la multiplicidad de actores, la necesidad de un abordaje que tenga en cuenta las nuevas realidades de la exclusión social, así como el introducir mejoras en materia de protección jurídica y dotación presupuestaria.

\section{Palabras Clave:}

Servicios sociales comunitarios, prestaciones económicas, análisis, rentas mínimas, exclusión social. 


\section{La configuración de los servicios sociales comunitarios}

\subsection{El Estado en la prestación de los servicios sociales}

En la segunda mitad del siglo XX, comienza a desarrollarse en la Europa Occidental el welfare state como modelo de protección social, debido en gran parte a las consecuencias que la II Guerra Mundial tuvo en nuestro continente y a cambios en la concepción del modelo capitalista, entre otros. Así, durante esa época, y con mayor énfasis, durante el período de 1950 a 1974, nuestro entorno se encuentra inmerso en una serie de cambios políticos, económicos y sociales respecto a los que España permanece ajena hasta el fin de la dictadura y la posterior transición democrática.

Tras la Guerra Civil Española, en nuestro país se establece un régimen dictatorial, caracterizado por una fuerte represión política y social, y un modelo económico basado en la autarquía, que prácticamente tuvo vigencia durante toda la dictadura, a pesar de que en la década de los sesenta el Plan Nacional de Estabilización (Decreto ley 10/1959) supusiera cierto aperturismo en materia económica y comercial, y en la participación de España en algunas organizaciones internacionales, como el Fondo Monetario Internacional o el Banco Internacional de Reconstrucción y Fomento. Tomando como referencia ese punto de inflexión histórico, Cerdeira (1987) plantea dos etapas que caracterizan la acción social durante el franquismo:

- Etapa de beneficencia del Estado: desde el inicio de la dictadura hasta la puesta en marcha del Plan Nacional de Estabilización.

- Etapa de asistencia social: que abarcaría desde la ejecución de aquél y se extendería hasta la aprobación de la Constitución y la configuración de un sistema de servicios sociales propiamente dicho, ya en el período democrático.

Pero si existe un elemento que va a marcar la configuración de los servicios sociales básicos es el Plan de Comunidad Cristiana de Bienes (en adelante, Plan (CB), cuya descripción merece una mención aparte. El Plan CCB, ideado por Cáritas para el período 1961-1964, tenía como objetivo principal la puesta en valor de la acción social comunitaria, con una fuerte inspiración cristiana. Surge del encargo a Cáritas Española del primer estudio sociológico sobre España ${ }^{1}$. Del informe se deduce la necesidad de promover una acción social comunitaria e integral que superara el asistencialismo imperante. Sus características principales podrían resumirse en tres:

- Pone especial énfasis en la acción social comunitaria, promovida desde una identificación

${ }^{1}$ Este informe daría pie a una serie de estudios, canalizada a través de la Fundación Foessa, que se convertiría en un clásico de la sociología aplicada de nuestro país. de las necesidades sociales de la población y de modelos precursores de la investigación-acción participativa.

- Critica los Planes de Desarrollo, por considerar que no tenían una visión integradora, ni promovían el desarrollo social como meta, sino que más bien éste se vía como una consecuencia del desarrollo económico.

- Introduce el concepto de centro social como canalizador de la acción social comunitaria, basada en una metodología profesional y una cartera estable de servicios.

Así pues, podemos plantear que si bien el telón de fondo del Plan CCB es el ejercicio organizado de la caridad (entendida como la redistribución de bienes entre los que los poseen y no) en el marco de la Iglesia, no debemos obviar que tanto en el desarrollo del Plan, como en el informe que lo origina, Cáritas plantea al Estado la necesidad de asumir su responsabilidad en cuanto a la protección social de los ciudadanos. Algunos conceptos presentes en el Plan, aunque con matices, han servido para la configuración posterior del sistema de servicios sociales comunitarios, como veremos más adelante, y suponen además un primer acercamiento institucional al paradigma de la normalización, frente a la de especialización imperante hasta el momento en toda la acción social del franquismo.

\subsection{Los servicios sociales y el período democrático}

Con la transición a la democracia, y la aprobación de la Constitución española en 1978, comienza un período de cambios sociales, políticos y económicos, que incidirán de forma directa en la organización territorial del Estado y de su administración, y por extensión, en la prestación de los servicios sociales. Aun así, no cumplió las expectativas, y a pesar de considerarse un texto abierto, algunos conceptos incluidos en ella, como el de beneficencia, contradecían el artículo 1 de la propia Carta Magna y venían a establecer ciudadanos 'de primera' y 'de segunda' categoría, dando por válido el concepto de 'graciabilidad'. El texto constitucional, además, no hace referencia alguna al concepto de servicios sociales como sistema universal, y tan sólo se puede encontrar una referencia expresa en el artículo 50, cuando alude a los servicios sociales para la tercera edad, encomendándole a éstos, la atención de los problemas de salud, cultura, vivienda y de ocio.

En cuanto a la asistencia social, aparece en el artículo 148.1.20, como competencia que podrán asumir las comunidades autónomas. Evidentemente, el concepto de asistencia social no es igual al de servicios sociales, como hemos visto en el apartado anterior, pero al menos hizo posible que se incluyera en el texto alguna referencia que permitiera la creación de un sistema de servicios sociales, aunque la competencia correspondiera únicamente a las comunidades autónomas. Debido 
a esto, hubo algunos intentos de promover una ley marco en materia de servicios sociales. En 1982, tras el intento frustrado de crear una ley nacional de servicios sociales, comenzaron a aparecer las primeras normas autonómicas de servicios sociales, siendo la del País Vasco la primera, en 1982, y la de la Comunidad Foral de Navarra la segunda, un año más tarde. Estas primeras leyes se centraron en el desarrollo y armonización de los servicios sociales especializados ya existentes, aunque no dejaron de lado el establecimiento de otro nivel de atención: el primario, básico o comunitario.

A escala estatal, la Ley $7 / 1985$, de 2 de abril, Reguladora de las Bases del Régimen Local asigna, en su artículo 25.2.k, la competencia de prestación de servicios sociales a los municipios, así como su obligatoriedad de prestación en aquellos municipios de más de 20.000 habitantes. Esta norma sentó un precedente importante en cuanto a la organización y funcionamiento de los servicios públicos, así como a su titularidad universal (art. 18.1.g), permitiendo a la ciudadanía que exigiera aquellos servicios de competencia municipal, y extendiendo ese derecho a la población extranjera domiciliada.

La obligación municipal de prestar servicios sociales se restringía únicamente a los municipios de más de 20.000 habitantes, sin que quedase claro a quién correspondía la competencia en municipios menores. Así mismo, la inconcreción del término "prestación de servicios sociales y de promoción y reinserción social” que plantea el artículo 25 dejaba al entendimiento del legislador municipal la configuración de los servicios sociales en cada municipio, atendiendo únicamente a las leyes autonómicas de servicios sociales si es que las había. Se necesitaba un instrumento que coordinara y armonizara la prestación de servicios sociales en todos los municipios.

Para ello, en 1988 nace el Plan Concertado de Prestaciones Básicas de Servicios Sociales. A finales de la década de los ochenta, han surgido ya algunas leyes autonómicas de servicios sociales, a pesar de lo cual la configuración del sistema público de servicios sociales sigue careciendo de una concreción y uniformidad que garanticen cierta homogeneidad en todo el territorio. La necesidad de incidir en la vida comunitaria, y de establecer un nivel primario de atención, que responda a las nuevas concepciones del paradigma de la normalización, frente al de la especialización, ya fue planteada en los años sesenta con el Plan CCB, como hemos visto en el apartado anterior. Es por ello por lo que, en un intento de unificar estos planteamientos (ya contemplados en las leyes autonómicas promulgadas a la fecha), surge el Plan Concertado, del que podemos destacar las siguientes características principales:

- Supone un logro sin precedentes de entendimiento y compromiso entre los tres niveles de la Administración del Estado.
- Establece servicios sociales básicos, públicos y gratuitos, mediante el compromiso de la cofinanciación. Fija un catálogo de prestaciones básicas en todo el territorio nacional (1998): información y orientación, apoyo a la unidad de convivencia y ayuda a domicilio, alojamiento alternativo, prevención e inserción y cooperación social.

- Crea una red de equipamientos: centro de servicios sociales, albergues y centros de acogida.

Es de destacar que, en un principio, el Plan Concertado no contemplaba las prestaciones económicas como prestación básica, aunque más tarde financiará las de emergencia social. Esta cuestión puede interpretarse como una oportunidad perdida para la creación de un sistema de rentas mínimas dependiente de los servicios sociales, pese a los intentos por parte del Ministerio competente en materia de Asuntos Sociales, a principios de la década de los noventa, de establecer un mecanismo de coordinación entre los distintos programas existentes en las comunidades autónomas (Laparra, 2004).

\subsection{El Estado autonómico y el desarrollo de la normativa de servicios sociales}

La aprobación en 1988 de la Ley 2/1988, de 4 de abril, de Servicios Sociales de Andalucía vino a completar el marco legislativo de los servicios sociales en esta comunidad autónoma, que había comenzado, en cuanto a producción normativa autonómica se refiere, con el Decreto 49/1986, de 5 de marzo, para la creación de los servicios sociales comunitarios de Andalucía, posterior a los reales decretos de traspaso de funciones y servicios de la Administración del Estado, promulgados entre 1982 y 1984 .

Básicamente, la Ley recoge los servicios que deben prestar los centros de servicios sociales comunitarios, estableciendo la Administración local como la competente para ello y reservándose la Administración autonómica las funciones de planificación general, supervisión y asesoramiento técnico, entre otras (art. 17). Es en el capítulo V donde se comienza a percibir un subsistema de prestaciones económicas que, como establece la Ley, será para quienes no puedan atender a sus necesidades básicas de subsistencia o estén en situación de extrema necesidad probada. Se trata de un concepto bastante ambiguo, que tendrá que ser desarrollado, que no garantiza las prestaciones por derecho (circunstancia común hasta nuestros días en los sistemas de servicios sociales), no aclara la Administración competente para probar las situaciones de necesidad descritas y enmarca las prestaciones económicas en el ámbito de la competencia autonómica, evitando que en un primer momento estas prestaciones se enmarcaran en el joven nivel de los servicios sociales comunitarios. 
El Decreto 11/1992, de 28 enero, por el que se establece la naturaleza y prestaciones de los servicios sociales comunitarios, vino a desarrollar el artículo 10 de la Ley, que establecía los servicios que habían de prestarse en el principal equipamiento de los servicios sociales comunitarios (los centros de servicios sociales), así como el compromiso y consolidación de la financiación de los servicios sociales comunitarios en Andalucía, a fin de garantizar los efectivos personales y funcionales, mediante la transferencia de medios a las entidades locales prestadoras. En un intento de homogeneizar determinadas órdenes dictadas desde la promulgación de Ley, el Decreto pretende su consolidación en un texto normativo e incorporar los preceptos derivados del Plan Concertado de Prestaciones Básicas de Servicios Sociales. De esta forma, se establecen, en el artículo 7, las prestaciones complementarias que deberán desarrollar los servicios sociales comunitarios, que serán suplementarias a las prestaciones técnicas o de servicios, estableciéndose dos tipos:

- Ayudas de emergencia social: prestaciones económicas individualizadas destinadas a paliar contingencias extraordinarias que se puedan presentar a personas o unidades familiares, y que deban ser atendidas con inmediatez.

- Ayudas económicas familiares: prestaciones temporales de carácter preventivo que se conceden a familias para la atención de las necesidades básicas de menores a su cargo cuando carecen de los recursos económicos suficientes, con el fin de evitar la institucionalización del menor y posibilitar su integración en el entorno familiar y social. Estas ayudas implicarán una intervención social complementaria y aportarán -como peculiaridad respecto a las ayudas de emergencia social- la gestión a través de acuerdos de cooperación entre la Junta de Andalucía y las entidades locales, como veremos más adelante.

\section{La perspectiva local. Las prestaciones económicas en el ámbito de los servicios sociales comunitarios del Ayuntamiento de Vélez-Málaga}

Acercarnos al estudio de las prestaciones económicas en el ámbito de los servicios sociales comunitarios supone delimitar y concretar el concepto de prestación económica, que tiene un sentido más amplio del que pueda entenderse en otros sistemas de protección social. Si bien la literatura científica no ha profundizado demasiado en este ámbito, sí podemos dar algunas notas definitorias de lo que entenderíamos por prestación o ayuda económica cuando nos referimos a la práctica del trabajo social en un ámbito individual/familiar con perspectiva comunitaria (Figura 1):

- La prestación no es un fin: es un medio para conseguir los objetivos de la intervención. La aportación económica se configura aquí como una estrategia coadyuvante en el proceso de intervención planteado con la persona o familia. Así, se tenderá a que la cuantía monetaria complementaria a la ayuda técnica tenga relación con objetivos de prevención, reducción o supresión de factores de riesgo.

- Se trata de un proceso de coproducción. Austin (2002) plantea que la producción efectiva de los servicios requiere de un proceso de coproducción con los usuarios, circunstancia que es y debe ser plenamente aplicable a la concesión de las prestaciones económicas de servicios sociales.

- La intervención gira en torno al contrato terapéutico consensuado con la persona o familia. Se debe dar respuesta a los objetivos en el marco de una relación profesional de ayuda, evitando o matizando las usuales asimetrías y relaciones de poder con los usuarios (Giménez Bertomeu y Doménech López, 2012), que condicionan el alcance de la intervención y la consecución de los objetivos profesionales.

Figura 1. Procedimiento de concesión de ayudas económicas de los servicios sociales

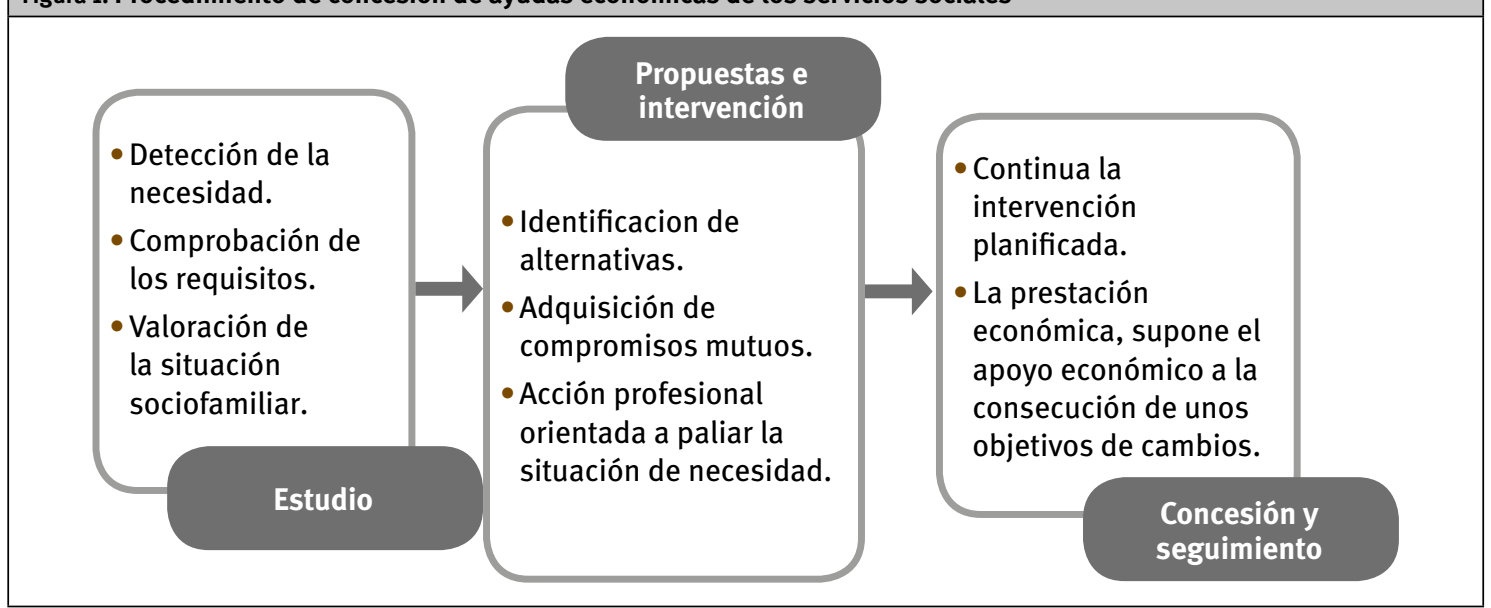

Fuente: Elaboración propia. 
Evidentemente, este planteamiento teórico y ético de la profesional del trabajo social y de la configuración de cualquier sistema público de protección social choca con algunas realidades, pues en ocasiones es complicado llevar a cabo un análisis tan riguroso de la situación sociofamiliar que nos permita conseguir objetivos de reinserción social. La inversión en servicios sociales resulta, por tanto, esencial para plantear mejoras cualitativas en la intervención con personas y familias. Podemos deducir aquí que los servicios sociales, como instrumento de las políticas sociales para alcanzar el bienestar en las sociedades complejas, actúan también como elementos de control social (Herrera Gómez y Castón, 2003), cuya función es también la de reproducción del sistema capitalista y el mantenimiento de las desigualdades entre la población.

En un plano descriptivo y desde el punto de vista local que estamos analizando, Vélez-Málaga es un municipio de la provincia de Málaga, con una población de 78.166 habitantes (Instituto Nacional de Estadística, 2015). Tiene Ayuntamiento propio, que ejerce la administración del municipio. En materia de servicios sociales de su competencia, cuenta con una zona de trabajo social (ZTS), que comprende todo el municipio, y siete unidades de trabajo social (UTS), que atienden a la totalidad de la población del municipio y su territorio. La mayor parte de ésta se concentra en los núcleos de Vélez-Málaga y Torre del Mar, que en los últimos años ha experimentado un aumento demográfico, con un ritmo de crecimiento superior al de la provincia, suponiendo dicha población más de la tercera parte de la totalidad de la comarca de la Axarquía. La dispersión territorial de la población es otro factor que considerar a la hora de la prestación de los servicios sociales, pues, a pesar de la concentración poblacional ya citada, el municipio cuenta con importantes y numerosos núcleos de población (Tabla 1).

Tabla 1. Núcleos de población del municipio de Vélez-Málaga

\begin{tabular}{l|c}
\hline Núcleo & $\begin{array}{c}\text { Población } \\
\text { (habs.) }\end{array}$ \\
\hline Almayate Alto & 26 \\
\hline Almayate Bajo & 1.679 \\
\hline Capitán, El & 120 \\
\hline Hornillo, El & 66 \\
\hline Monte Azul & 21 \\
\hline Tajo del Pinto & 25 \\
\hline Toscanos, Los & 129 \\
\hline Benajarafe & 2.376 \\
\hline Puertas, Los & 176 \\
\hline Cajiz & 399 \\
\hline Íberos & 162 \\
\hline Caleta de Vélez & 3.361 \\
\hline
\end{tabular}

\begin{tabular}{l|c}
\hline Núcleo & $\begin{array}{c}\text { Población } \\
\text { (habs.) }\end{array}$ \\
\hline Chilches & 3.266 \\
\hline Lagos & 223 \\
\hline Mezquitilla & 272 \\
\hline Tomillar, El & 1.697 \\
\hline Torre del Mar & 19.951 \\
\hline Trapiche & 174 \\
\hline Aldea Baja & 9 \\
\hline Triana & 468 \\
\hline Zorrilla & 36 \\
\hline Vélez-Málaga & 39.662 \\
\hline Diseminados & 3.868 \\
\hline
\end{tabular}

Fuente: Instituto de Estadística y Cartografía de Andalucía (2015).

El Ayuntamiento de Vélez-Málaga no cuenta con un instrumento estratégico o plan específico para el desarrollo de sus servicios sociales municipales, remitiéndose éstos a la legislación vigente estatal, autonómica y a la normativa municipal relativa a ayudas económicas de emergencia social, ayudas económicas familiares y reglamento de ayuda a domicilio municipal, de la que se deducen la estructura, organización y funcionamiento de los servicios sociales municipales. Esta carencia de instrumento de política social propicia una falta de visión general y misión estratégica necesaria, para además de regular las condiciones, estructura y organización de los servicios sociales comunitarios, plantear objetivos de bienestar y desarrollo social. Si bien en los últimos años se ha realizado un importante esfuerzo para elaborar una estrategia municipal de desarrollo urbano sostenible (Ayuntamiento de Vélez-Málaga, 2015a), debe darse traslado de esas directrices generales al contexto y realidad social, para poder implementar políticas sociales que se adecuen a las necesidades del municipio.

La planificación estratégica a escala municipal persigue establecer y definir las líneas de acción que se habrán de desarrollar en los años inmediatos con el objetivo de aumentar la coherencia del sistema de servicios sociales del municipio, determinar prioridades y garantizar, en consecuencia, el mejor cumplimiento de los fines que la legislación encomienda. El plan municipal de servicios sociales, como herramienta de planificación estratégica, es un modelo de acción a largo plazo (inversiones, servicios, participación, calidad), que conlleva una serie de ventajas (Ayuntamiento de Medina del Campo, 2004: 2):

- Expresa un consenso entre las fuerzas políticas sobre el modelo de servicios sociales y las principales líneas de actuación. Los esfuerzos de todos se traducirán del qué al cómo.

- Supone una gestión estratégica: se trabaja de acuerdo con objetivos estratégicos, a partir de indicadores de evaluación de la implantación de las medidas y de la evolución del entorno.

- Facilita la elaboración de políticas sectoriales.

- Simplifica la elaboración de planes plurianuales de inversiones y de actuaciones.

- Evita solapamientos y vacíos en las actuaciones, previniendo políticas divergentes 0 incompatibles.

- Supone una oportunidad para implantar las metas por objetivos y el control de gestión en todos los niveles de las organizaciones.

- Establece compromisos de actuación con la ciudadanía, y permite que ésta conozca y monitorice la actividad pública.

Para que la planificación estratégica resulte efectiva, antes deben resolverse varias cuestiones. Sobre este aspecto, Precedo Ledo (1994, cit. en Cordero Martín, 2006) resalta: 
- La necesidad de concebir la planificación como un instrumento al servicio de la sociedad, lo cual requiere, necesariamente, su participación activa.

- La dificultad de poseer esquemas válidos de anticipación en todos los campos necesarios, lo cual sería básico de acuerdo con el carácter prospectivo que debería tener.

- La necesidad de diseñar modelos o esquemas de planificación territorial asociados a los diferentes ritmos de crecimiento económico.

- La dificultad de diseñar metodologías válidas que, partiendo de los objetivos de las políticas sectoriales, logren integrarlas en el territorio, de acuerdo con los atributos diferenciales que éste posee.

Aun así, la ausencia de una planificación estratégica que enmarque la acción social del municipio en Vélez-Málaga puede deberse a otros factores de índole menos procedimental, sino más relacionados con la cultura organizacional. Aunque no es objeto de nuestro análisis, podríamos decir que la falta de cultura de planificación que regule las normas y la burocracia interna de una organización se enmarcaría en el plano de las presunciones básicas subyacentes (Schein, 1985; Peiró, 1990), como resistencia propia de la organización al control externo, y tendrían las siguientes características:

- Son preconscientes, se dan por consolidadas.

- Son difíciles de cambiar.

- Hacen referencia a la naturaleza de la realidad, el tiempo, el género humano, la actividad y las relaciones.

- Implican menor accesibilidad y mayor subjetividad.

- Son el núcleo esencial de la cultura en sí.

Otro asunto digno de considerar es la contextualización actual de los servicios sociales comunitarios, el nuevo escenario de cambio en el que están inmersos desde la promulgación de la Ley $27 / 2013$, de 27 de diciembre, de Racionalización y Sostenibilidad de la Administración Local, que supone una importante amenaza tanto para la configuración del sistema desde el punto de vista de la atención y protección a la ciudadanía como desde la perspectiva de los profesionales, cuyos puestos de trabajo quedan en cuestión. En este sentido, es difícil prever las repercusiones de la nueva normativa de régimen local, aunque algunos autores señalan, entre otras, la pérdida de derechos para la ciudadanía y la apertura de una vía para la externalización y la pérdida de responsabilidad pública de algunos servicios que ahora se prestan de forma directa (Uceda et al., 2013). La reforma se ha realizado bajo el mandato de la contención del gasto público y el pretexto de la racionalización y de evitar duplicidades en la prestación de servicios, y viene a dar en la línea de flotación de un sistema ya de por sí vulnerable.
Este escenario de gran adversidad exige que los servicios sociales se conviertan en un instrumento del sistema de protección social con responsabilidades últimas en la cobertura de las necesidades básicas de un importante grupo de población. Las dificultades para financiarlo, unido a un contexto complejo y dinámico, requieren un abordaje desde perspectivas que aseguren un correcto ajuste de la realidad con los recursos ofertados. Sobre este aspecto, resulta muy interesante la incorporación al ámbito local de metodologías que estudien el comportamiento organizacional y garanticen que los esfuerzos para hacer frente a las demandas se dirigen en la dirección correcta. Destacan dos conceptos: el de adaptación, definido por Lengnick-Hall, Beck y Lengnick-Hall (2011) y que implica el objetivo de un funcionamiento organizacional optimizado con el entorno; y el de resiliencia organizacional, que plantean Lee, Vargo, y Seville (2013) al referirse a la capacidad de las organizaciones de afrontar situaciones imprevistas y traumáticas, y continuar funcionando de una manera adecuada

\subsection{Las ayudas de emergencia social}

Las ayudas de emergencia social constituyen, en términos de transferencias, uno de los principales instrumentos de las políticas municipales para la lucha contra la exclusión social en el Ayuntamiento de Vélez-Málaga, encuadrados en los servicios sociales comunitarios y destinados a paliar las contingencias extraordinarias que se puedan presentar a personas o unidades familiares y que deben ser atendidas con inmediatez. Su concesión se regula mediante un reglamento municipal, aprobado por el Pleno de la corporación y sometido a exposición pública, siendo el texto vigente el publicado en 2016 (Boletín Oficial de la Provincia de Málaga, no 101, de 30 de mayo). Con respecto al anterior, de 2010, actualiza conceptos y cuantías, incorporando una mayor intensidad en la protección de desahucios y para garantizar el acceso a los suministros básicos. Cuenta con una consignación presupuestaria para el ejercicio 2016 de $330.000 €$. En un análisis del texto del reglamento, podemos destacar los objetivos de la prestación:

- Objetivo general: contribuir a la evolución favorable de las situaciones de necesidad y al establecimiento de unas mejores condiciones de vida para el individuo o unidad de convivencia, apoyando las prestaciones básicas que establezcan o hayan establecido los servicios sociales comunitarios.

- Objetivo específico: dotar de recursos económicos a la persona o unidad de convivencia para que pueda salir de la situación generada por la propia carencia de recursos económicos u otras de carácter coyuntural.

El reglamento distingue entre población objeto y destinatarios de la población, conceptos 
asimilados a los de población potencial/diana y beneficiarios directos. Es de destacar que las ayudas de emergencia social van dirigidas a unidades familiares, aun cuando se propongan para solventar situaciones de uno o parte de sus miembros, lo que en ocasiones puede condicionar la intervención que se vaya a plantear, ya que los modelos de familia son cambiantes y no responden a patrones estrictos:

- Población objeto: personas o unidades de convivencia que, debido a situaciones coyunturales y con escasos o nulos ingresos económicos, no puedan, de forma inmediata, atender sus dificultades y no tengan a su alcance otro recurso que pueda resolver la situación en que se encuentran. En este sentido, se considera la prestación económica como un apoyo para solucionar los problemas en que se encuentran inmersos.

- Destinatarios de la prestación: personas que, formando parte de la población objeto, demanden la intervención de los servicios sociales comunitarios y se comprometan a llevar a cabo los cambios acordados con la persona profesional de referencia en la intervención.

Desde un análisis centrado en la intervención profesional, podemos destacar que las Ayudas de emergencia social facilitan la atención de las demandas de carácter coyuntural, actuando como coadyuvantes de las actuaciones que se puedan desarrollar, en el marco de los servicios sociales comunitarios, para mejorar la autonomía de la persona o familia, y conseguir su desarrollo. Aunque no impliquen de forma directa un itinerario de inserción social, sí establecen una serie de compromisos con los beneficiarios, dependiendo de la situación y la contingencia a cubrir. Estos compromisos no se encuentran regulados, $y$ serán los que se determinen y acuerden entre el profesional de referencia en el caso (trabajador/a social) y la familia beneficiaria, teniendo en cuenta las características sociofamiliares y los objetivos planteados.

\begin{tabular}{|c|c|c|}
\hline Concepto & Definición & Cuantías \\
\hline Alojamiento & $\begin{array}{l}\text { Actuaciones que se concretan en la prestación para prevenir } \\
\text { situaciones que pudieran derivar en la privación de la } \\
\text { vivienda habitual, entendiéndose incluidas las deudas } \\
\text { derivadas de alquiler o hipoteca. }\end{array}$ & $\begin{array}{l}\text { Hasta el } 100 \% \text { del concepto, con un máximo de } 1.500 € \\
\text { al año, prorrateado o en pago único }\end{array}$ \\
\hline $\begin{array}{l}\text { Alojamiento } \\
\text { alternativo }\end{array}$ & $\begin{array}{l}\text { Derivado de situaciones sobrevenidas y que requieran } \\
\text { atención especializada mientras se tramitan otros recursos. }\end{array}$ & $\begin{array}{l}\text { Hasta el } 100 \% \text { del concepto, con un máximo de } \\
2.000 € \text { anuales. }\end{array}$ \\
\hline Hospedaje & $\begin{array}{l}\text { Alojamiento temporal para situaciones de necesidad } \\
\text { y urgencia social, cuando no exista otra alternativa de } \\
\text { recurso. }\end{array}$ & $\begin{array}{l}\text { Hasta el } 100 \% \text { del concepto, con un máximo de } 50 € / \\
\text { día/individuo y un total de } 7 \text { días. }\end{array}$ \\
\hline Alimentación & $\begin{array}{l}\text { Apoyo económico para la cobertura de las necesidades } \\
\text { básicas de alimentación de la familia }\end{array}$ & $\begin{array}{l}\text { Hasta el } 100 \% \text { del concepto, con un máximo de } 1.500 € \\
\text { por individuo o unidad de convivencia al año. }\end{array}$ \\
\hline $\begin{array}{l}\text { Suministros } \\
\text { mínimos vitales }\end{array}$ & $\begin{array}{l}\text { - Gastos de energía eléctrica producidos desde el momento } \\
\text { en que no se puede hacer frente a la tarifa contratada. } \\
\text { - Gastos derivados del suministro de agua producidos } \\
\text { desde el momento en que no se puede hacer frente a la } \\
\text { tarifa contratada. }\end{array}$ & $\begin{array}{l}\text { Hasta el } 100 \% \text { del concepto, según la siguiente } \\
\text { distribución: } \\
\text { - Energía eléctrica: hasta } 3 \text { recibos, con un máximo } \\
\text { de } 400 € \text {. } \\
\text { - Suministro de agua: hasta } 3 \text { recibos, con un máximo } \\
\text { de } 300 € \text {. }\end{array}$ \\
\hline Desplazamiento & $\begin{array}{l}\text { Desplazamiento a centros de tratamiento especializados, } \\
\text { juzgados o centros penitenciarios que no puedan ser } \\
\text { asumidos por el usuario o la familia. }\end{array}$ & $\begin{array}{l}\text { El gasto real, con los límites máximos que establece el } \\
\text { reglamento. }\end{array}$ \\
\hline Comedor & $\begin{array}{l}\text { Situación excepcional que conlleve la imposibilidad de } \\
\text { preparar alimentos en el propio hogar y, por tanto, la no } \\
\text { inclusión en el concepto alimentación. }\end{array}$ & Hasta $1.500 €$ por unidad de convivencia al año. \\
\hline Farmacia & $\begin{array}{l}\text { Situaciones apremiantes y de vital necesidad de salud que } \\
\text { necesitan un tratamiento, prescrito por médico del Sistema } \\
\text { Andaluz de Salud, que no pueda asumir el interesado de } \\
\text { forma puntual. }\end{array}$ & $\begin{array}{l}\text { Hasta el } 80 \% \text { del concepto, con un máximo de } 1.500 € \\
\text { anuales. }\end{array}$ \\
\hline $\begin{array}{l}\text { Mobiliario y } \\
\text { enseres }\end{array}$ & $\begin{array}{l}\text { Compra de enseres y mobiliario de primera necesidad y en } \\
\text { situaciones excepcionales. }\end{array}$ & Hasta el $70 \%$ del concepto, con un máximo de $1.500 €$. \\
\hline $\begin{array}{l}\text { Otros que la } \\
\text { dinámica social } \\
\text { exija }\end{array}$ & $\begin{array}{l}\text { Situaciones poco frecuentes, de carácter excepcional y } \\
\text { debidamente acreditadas, en las que sea necesario un } \\
\text { apoyo económico y una intervención de los servicios } \\
\text { sociales. }\end{array}$ & Hasta $1.500 €$ \\
\hline
\end{tabular}

Fuente: Elaboración propia. 


\section{Las ayudas económicas familiares}

Desde de la entrada en vigor de la Orden de 20 de abril de 1992, de la Consejería de Asuntos Sociales, por la que se establecen las normas que han de regir la colaboración entre la Junta de Andalucía y las corporaciones locales de su territorio en materia de ayudas económicas familiares para la atención al niño, los servicios sociales de Andalucía disponían de un instrumento para proveer de prestaciones económicas a familias con menores que se encontraran en situación de dificultad social. Con la consolidación de los servicios sociales comunitarios, y ya avanzada la década de los noventa, se vio la necesidad de ampliar este tipo de prestaciones (que estaban circunscritas a determinadas entidades locales que habían suscrito un convenio de colaboración de acuerdo con determinadas características sociodemográficas) al resto de entidades locales que prestaban servicios sociales comunitarios.

Es entonces cuando surge la Orden de 13 abril de 1998, por la que se regulan las ayudas económicas familiares y su gestión mediante la cooperación entre la Junta de Andalucía y las corporaciones locales de su territorio. Se articulaba así, un instrumento jurídico, en forma de convenio, abierto a todos los Ayuntamientos y diputaciones con competencias (en la actualidad, 81 Ayuntamientos y 8 diputaciones provinciales), para dar cumplimiento al Decreto 11/1992. Pero en lugar de optar por una transferencia general de crédito consolidado, se optó por el convenio individual entre la entidad local y la Junta de Andalucía, que aunque arraigado en el tiempo, no garantizaba la aportación de la Administración autonómica, con el consiguiente perjuicio para los beneficiarios de las prestaciones. De esta forma, estas prestaciones se enmarcan en las denominadas 'complementarias' de los servicios sociales, formando parte de la estructura de los servicios sociales municipales, aunque un porcentaje de su financiación y el objeto general que subvenciona están regulados por la Junta de Andalucía.

Con la publicación de la Orden de 10 de octubre de 2013, la Junta de Andalucía da un paso adelante en la consolidación de estas prestaciones, cerrando un camino que ya había comenzado el Decreto ley 7/2013, de 30 de abril, de Medidas Extraordinarias y Urgentes para la Lucha contra la Exclusión Social en Andalucía, que establecía la ampliación de la financiación para estas ayudas, además de suponer la inclusión de éstas (y por extensión, de los servicios sociales comunitarios) en los primeros instrumentos normativos para hacer frente a la situación socioeconómica derivada de la crisis. Otro aspecto destacable del citado texto normativo es el de no someter la prestación a las disposiciones aplicables a las subvenciones públicas, al hallarse expresamente excluidas de su ámbito de aplicación, de acuerdo con lo dispuesto en los artículos 2.2 de la Ley 38/2003, de 17 de noviembre, General de Subvenciones y demás normativa autonómica de aplicación, lo que solucionaba un problema que ha generado importantes inconvenientes fiscales y para el acceso a otros recursos públicos a las familias beneficiarias de estas prestaciones.

En esta norma, las ayudas económicas familiares se consideran una prestación complementaria de los servicios sociales comunitarios y se definen como prestaciones temporales, dinerarias o en especie, de carácter preventivo, que se conceden a las familias para la atención de necesidades básicas de los y las menores a su cargo, especialmente de crianza y alimentación, y con un claro enfoque en la prevención y la intervención en situaciones de riesgo y exclusión social. A pesar de la novedad aportada por la Orden, no se consiguió establecer un marco normativo homogéneo en toda Andalucía, ya que únicamente consigna la cantidad comprometida por la Administración autonómica. De esta forma, la cofinanciación en el resto de municipios queda a criterios de voluntad política, sostenibilidad y disponibilidad presupuestaria, estableciéndose importantes diferentes entre los distintos territorios. En el caso de Vélez-Málaga (2015b), un reglamento municipal desarrolla el contenido de la Orden y la gestión de las prestaciones en el municipio, estableciendo una serie de objetivos y de consideraciones para gestionarlas:

- Se enmarcan en la prevención, reducción o supresión de factores que generen situaciones de dificultad social para los menores, previamente identificados por las personas profesionales de los servicios sociales comunitarios.

- Su misión es evitar la institucionalización y posibilitar su integración en el entorno familiar y social cuando la permanencia del menor fuera de aquél se deba fundamentalmente a la carencia de recursos económicos para la cobertura de las necesidades básicas.

- Se integran como medida coadyuvante al desarrollo de un proyecto de intervención familiar dirigido a la mejora de la dinámica familiar y la supresión de los factores de riesgos para los menores.

- La intervención cuenta con un pronóstico positivo sobre la resolución de las dificultades que afectan a los menores.

- Las personas destinatarias aceptan la intervención de los servicios sociales comunitarios, comprometiéndose a cumplir los objetivos acordados con los profesionales en el proyecto de intervención familiar.

De la lectura del reglamento se deduce, la necesidad de una intervención previa con la familia, lo que condiciona la población destinataria, que debe, en primer lugar, expresar su demanda en los servicios sociales comunitarios. Así mismo, se contempla la obligatoriedad de establecer nuevos compromisos -tanto para el usuario como para el profesionalde cara al cumplimiento de los objetivos de inserción 
social, compromisos que permitan, además, la evaluación continua de la intervención. La prestación puede percibirse de forma mensual, mientras se mantengan las circunstancias que motivaron su concesión, según conste en el proyecto de intervención familiar acordado con los beneficiarios. Además, se establecen una serie de requisitos administrativos (vecindad, composición familiar) y económicos, que toman como referencia el indicador público de renta de efectos múltiples (IPREM), estableciéndose que el procedimiento sólo se podrá iniciar de oficio en el marco de una intervención social previa con la familia.

Las ayudas económicas familiares cuentan, en el presupuesto municipal, con un crédito inicial de
325.000 € para el ejercicio 2016. Desde el punto de vista técnico, los criterios básicos para su concesión contemplan:

- La situación sociofamiliar: presencia de indicadores de riesgo, composición familiar, dinámica relacional y grado de implicación de la familia en la solución de problema.

- La situación económica, valorando que la carencia e insuficiencia de recursos económica no dificulte la adecuada cobertura de las necesidades básicas del menor en su unidad familiar.

- Las características de la vivienda, teniendo en cuenta las condiciones de habitabilidad y entorno social.

\begin{tabular}{|c|c|c|}
\hline Concepto & Definición & Cuantías \\
\hline Necesidades básicas & $\begin{array}{l}\text { Adquisición de alimentos, ropa, calzado, productos } \\
\text { de aseo personal e higiene doméstica, provisión de } \\
\text { leche de continuidad y pañales También se incluyen } \\
\text { productos farmacéuticos, ópticos, ortopédicos y } \\
\text { protésicos con prescripción facultativa y que no puedan } \\
\text { ser cubiertos por el sistema público de salud. }\end{array}$ & $\begin{array}{l}\text { - Familias con un/a menor: } 50 \% \text { de IPREM mensual } \\
(266 € / m e s) \text {. } \\
\text { - Familias con dos menores: } 306 € / \text { mes. } \\
\text { - Familias con tres menores: } 332 € / \text { mes. } \\
\text { - Familias con cuatro menores: } 359 € / \text { mes. } \\
\text { - Familias con más de cuatro menores: } 93 € / \text { mes } \\
\text { adicionales por cada menor a partir del quinto. }\end{array}$ \\
\hline \multirow{4}{*}{ Otras necesidades } & $\begin{array}{l}\text { Material escolar no financiado por la Consejería } \\
\text { competente en materia de Educación. }\end{array}$ & $\begin{array}{l}\text { El total del gasto subvencionable, hasta un máximo } \\
\text { de } 200 € \text {. }\end{array}$ \\
\hline & $\begin{array}{l}\text { Escuelas infantiles, siempre que se hayan agotado, } \\
\text { o estén en trámite, recursos educativos reglados y } \\
\text { se trate de menores a los que se haya valorado una } \\
\text { situación de riesgo social extremo. }\end{array}$ & $\begin{array}{l}\text { Como máximo, el precio tasado por la Administración } \\
\text { competente para plaza concertada en escuelas } \\
\text { infantiles de titularidad pública. }\end{array}$ \\
\hline & $\begin{array}{l}\text { Logopeda: con prescripción facultativa y durante la } \\
\text { vigencia de la ayuda. Será incompatible con becas u } \\
\text { otras prestaciones de análoga naturaleza. }\end{array}$ & $\begin{array}{l}100 € / \text { mes por cada menor que lo necesite dentro de } \\
\text { la unidad familiar. }\end{array}$ \\
\hline & $\begin{array}{l}\text { Se podrán subvencionar desplazamientos con } \\
\text { continuidad y con periodicidad conocida relacionados } \\
\text { con la intervención que se esté llevando a cabo con } \\
\text { la unidad familiar: a escuelas-hogar, residencias } \\
\text { escolares, centros hospitalarios, juzgados, centros de } \\
\text { reforma o penitenciarios, entre otros. }\end{array}$ & $\begin{array}{l}\text { - Menores de } 3 \text { años: } 10 € \text { por desplazamiento (sólo } \\
\text { cubre el gasto del acompañante). } \\
\text { - Mayores de } 3 \text { años: } 20 € \text { por desplazamiento } \\
\text { (cubre el gasto del menor y de su acompañante). }\end{array}$ \\
\hline \multirow{4}{*}{$\begin{array}{l}\text { Necesidades } \\
\text { excepcionales }\end{array}$} & $\begin{array}{l}\text { Alquiler: las actuaciones de este concepto se concretan } \\
\text { en la prestación para prevenir situaciones que } \\
\text { pudieran derivar en la privación de la vivienda habitual. }\end{array}$ & $\begin{array}{l}\text { Hasta el } 50 \% \text { del coste mensual de la vivienda } \\
\text { (alquiler o hipoteca), con un tope máximo de } 225 € / \\
\text { mensual, durante un período máximo de } 6 \text { meses. }\end{array}$ \\
\hline & $\begin{array}{l}\text { Suministros básicos de electricidad, gas y agua. } \\
\text { Mediante la justificación en estos conceptos, de las } \\
\text { cantidades percibidas por necesidades básicas. }\end{array}$ & Hasta un máximo de $200 €$ al año. \\
\hline & $\begin{array}{l}\text { Adquisición de mobiliario y enseres básicos, que } \\
\text { directamente incidan en el bienestar del menor. }\end{array}$ & $\begin{array}{l}\text { Hasta el } 70 \% \text { del concepto, con un máximo de } \\
1.500 € \text { anuales. }\end{array}$ \\
\hline & $\begin{array}{l}\text { Otros conceptos que así se recojan motivadamente por } \\
\text { el profesional de referencia en el informe social. }\end{array}$ & $\begin{array}{l}\text { Cuantías y máximos, similares a conceptos análogos } \\
\text { ya existentes en el reglamento. }\end{array}$ \\
\hline
\end{tabular}

IPREM: indicador público de renta de efectos múltiples.

Fuente: Elaboración propia. 


\section{Otras prestaciones que requieren la intervención directa de los servicios sociales comunitarios}

\subsection{Prestaciones económicas del Sistema para la Autonomía y Atención a la Dependencia}

Tras la aprobación de la Ley 39/2006 de 14 de diciembre de Promoción de la Autonomía Personal y Atención a Personas en Situación de Dependencia, se estableció en nuestro país un nuevo modelo de atención al colectivo de personas con discapacidad y mayores, que ha tenido importantes repercusiones en el sistema público de servicios sociales. La Ley, que llegaba con una vocación integradora, aunque sin las pretensiones de una ley marco estatal, configuró un nuevo sistema de atención, que, en su desarrollo, ha llevado a importantes diferencias en función de la comunidad de aplicación. Así mismo, suponía la configuración de un sistema de servicios sociales garantista, que ofrece prestaciones y servicios de derecho subjetivo, a diferencia de lo que hasta entonces se planteaba en este ámbito. Tener una fuerte inspiración en el modelo médico, con prestaciones de marcado carácter asistencialista (Guzmán, Moscoso y Toboso, 2010), no es obstáculo para considerar que la Ley "constituye un avance incuestionable en el desarrollo de los derechos sociales en España, que ha sido posible en el ámbito de consenso político del Pacto de Toledo" (Rodríguez Cabrero, 2007: 83).

A pesar del carácter innovador de la norma, ha adolecido de un pacto de Estado tras su puesta en marcha que hubiera fijado de forma consensuada el nivel de protección, evitando desigualdades territoriales y manteniéndola ajena a los movimientos políticos. Esto, unido a importantes déficits en la distribución competencial y en el modelo de financiación (Cervera et al., 2012), ha dificultado una correcta evaluación sobre la conveniencia de la norma en nuestro modelo de protección social, que hubiera necesitado de al menos una década para su consolidación y perfeccionamiento (Rodríguez Cabrero, 2007).

En Andalucía, tras la aprobación del Decreto $168 / 2007$, de 12 de junio, se optó por integrar toda la atención a la dependencia en el sistema público de servicios sociales (art. 3), y dejar en manos de los servicios sociales comunitarios las tareas de información al ciudadano, de instrucción del expediente administrativo para el reconocimiento de la situación de dependencia, y de elaboración de la propuesta del programa individual de atención de la persona reconocida como dependiente a quien, según la aplicación progresiva de la Ley, le corresponda recibir prestaciones o servicios. Este reparto competencial, que puede verse como una importante carga de trabajo adicional a un sistema ya colapsado, supone, por otro lado, una oportunidad de integrar la atención primaria al colectivo de personas con dependencia en los servicios sociales comunitarios, imbricando sus servicios y prestaciones con otras que se prestan en estos dispositivos a las personas y familias. Si bien no queda establecido en dicho reparto quién se va a encargar del seguimiento de esas prestaciones y servicios, cabe deducir que de ello se encargarán los servicios sociales comunitarios (Villalobos, 2008), que, como servicios más próximos al ciudadano, deben asegurar la prestación o servicio, y los fines para los que se prescribió.

En cuanto a la prescripción, a los servicios sociales comunitarios se les abre una nueva vía de intervención, en la que, aplicando su criterio profesional, pueden proponer una serie de prestaciones y servicios que mejoren la calidad de vida de la unidad familiar en su conjunto, y no sólo de la persona dependiente. Es posible que, a partir de la inconcreción de la Ley en este sentido, se haya planteado una intervención integral cercana al ciudadano, pues para llevar a cabo esta propuesta, los servicios sociales comunitarios deberán realizar un informe en el que se detalle la situación social, familiar y del entorno de la persona en situación de dependencia (art. 17.3 del Decreto 168/2007). En el ámbito de las prestaciones económicas, al igual que en el de los servicios que contempla la Ley, es necesaria la prescripción dentro del programa individual de atención, que habrá de tomar en cuenta las circunstancias sociofamiliares de la persona en situación de dependencia y garantizar la modalidad de atención más adecuada. De esta forma, distinguimos:

- Prestación económica para el cuidado en el entorno familiar, de carácter excepcional, destinada a aquellos casos en los que la persona en situación de dependencia está siendo atendida por su entorno familiar y se dan las condiciones de acceso establecidas. A lo largo de la vigencia de la Ley, se han endurecido las condiciones de acceso, se ha suprimido la inclusión de las cotizaciones para los cuidadores y han disminuido las cuantías, a la vez que se ha constatado cómo la excepcionalidad prevista en la Ley se ha convertido en práctica habitual (Cervera et al., 2012; López Casanovas y Del Pozo Rubio, 2010).

- Prestación económica vinculada a un servicio, que se dirige a aquellos casos en los que no hay posibilidad de acceder a un servicio público o concertado, destinándose la prestación a financiar el coste de aquél en recursos privados, pero debidamente acreditados ante la Administración.

- Prestación económica de asistencia personal: destinada a contribuir a la cobertura de los gastos derivados de la contratación de una persona profesional para apoyar a la persona en situación de dependencia a realizar determinadas tareas de carácter básico, o bien para facilitar su acceso al ocio, al empleo, a actividades formativas o de participación (asistente personal). Si bien se trata de un gran avance inclusivo para las 
personas en situación de dependencia, su aplicación práctica está siendo insatisfactoria y escasa por parte de las Administraciones, tal como señala López-Pérez (2012), que resalta la inexistencia de legislación de desarrollo, la reducida disponibilidad presupuestaria y la falta de voluntad política como factores que explican su insuficiente implantación.

\subsection{El Programa de Solidaridad de los Andaluces y los servicios sociales comunitarios}

Al comienzo de la década de los noventa del siglo pasado, comienzan en Andalucía una serie de experiencias orientadas a dotar a la población de un ingreso mínimo de inserción, que, como complemento al resto de políticas de protección social, permitiera redistribuir la renta y la riqueza. Este proceso no es único, y surge de forma paralela en otras comunidades autónomas, que empiezan a desarrollar sus competencias constitucionales en materia de servicios sociales. En Andalucía, el denominado Programa de Solidaridad de los Andaluces para la Erradicación de la Marginación y la Desigualdad surge con vocación de inserción social y carácter proactivo, dejando a un lado las estrategias puramente asistenciales que habían impregnado hasta entonces las políticas sociales en España.

El Decreto 2/1999, de 12 de enero, por el que se regula la creación del Programa sienta las bases para configurar un sistema de rentas mínimas en Andalucía, aunque con limitaciones y diferencias sustanciales con otros territorios, principalmente en lo referente a la garantía de su percepción y a la duración del cobro (Pacheco-Mangas y HernándezEchegaray, 2014). Con la publicación del Decreto ley $7 / 2013$, de 30 de abril, de medidas extraordinarias y urgentes para la lucha contra la exclusión social en Andalucía, se modifican diversos apartados del Programa con la intención de dotarlo de una mayor agilidad en los procesos de valoración y concesión, situándose el plazo máximo para la resolución motivada de las solicitudes en los dos meses desde su presentación.

Como otros programas de rentas mínimas, toma como referencia para ser beneficiario a las unidades familiares o de convivencia, que deberán cumplir una serie de requisitos administrativos y económicos entre los que se encuentran (art. 2 del Decreto 2/1999):

- Estar constituidas de forma estable, con un año de antelación, como mínimo, a la fecha de la solicitud, salvo en los casos de matrimonio, nacimiento de hijo o adopción, y ruptura familiar suficientemente acreditada.

- Estar todos sus miembros empadronados como residentes en un mismo domicilio, ubicado en un municipio de la comunidad autónoma de Andalucía, al menos con un año de antelación a la fecha de presentación de la solicitud.
No obstante, podrán admitirse excepciones a la residencia continuada cuando estén motivadas por causas de trabajo o análogas, así como por fuerza mayor.

- Disponer de unos recursos mensuales inferiores a la cuantía del ingreso mínimo de solidaridad, calculada conforme establece el artículo $6.1 \mathrm{del}$ Decreto 2/1999, si bien tomando como referencia el salario mínimo interprofesional vigente en la fecha de presentación de la solicitud.

Una vez comprobado el cumplimiento de los requisitos, se concede la prestación, que consiste en el cobro del ingreso mínimo de solidaridad durante un período máximo de seis meses, acompañado de otras medidas, como itinerarios profesionales, medidas educativas o de acceso a la vivienda. Dado su carácter de prestación proactiva, los beneficiarios deben cumplir una serie de obligaciones para mantenerse como beneficiarios del Programa (art. 11 del Decreto 2/1999):

- Comunicar a la delegación territorial competente, en el plazo máximo de quince días, la modificación sobrevenida de las circunstancias que determinaron la concesión de las acciones previstas en el Decreto.

- Solicitar las prestaciones, contributivas o no contributivas, así como reclamar los derechos que, por cualquier título, pudiera corresponderles a fin de incrementar sus recursos económicos, ejerciendo las acciones pertinentes para hacerlos efectivos.

- No rechazar oferta de empleo adecuada, ni cualquiera de las acciones previstas en el Programa de Solidaridad.

- Prestar a la Administración la colaboración necesaria para una eficaz gestión del citado Programa.

- Firmar y cumplir el compromiso de inserción que, en su caso, se establezca y realizar las actividades fijadas en él.

- Reintegrar las cantidades indebidamente percibidas.

Si bien estamos ante una prestación cuya gestión corresponde íntegramente a la Consejería competente en materia de servicios sociales en Andalucía (en la actualidad, la Consejería de Igualdad y Políticas Sociales), el hecho de que pueda solicitarse en cualquier municipio de Andalucía, así como su carácter 'universal' (a pesar de que restringe su aplicación a los nacionales de países de la Unión Europea), ha llevado a los servicios sociales comunitarios a incluir esta prestación en el itinerario de inserción establecido con la persona o familia. Básicamente, la prestación ha incidido en los servicios sociales comunitarios de la siguiente manera:

- La prestación económica del programa y el resto de actuaciones se incorporan a la intervención 
que los servicios sociales comunitarios realizan con la persona o familia, propiciando un seguimiento directo, cercano al ciudadano, que complementa otras actuaciones o prestaciones de competencia municipal.

- Las circunstancias sociofamiliares no acreditables documentalmente, tan comunes en un determinado perfil de usuarios de servicios sociales (ausencia de empadronamiento, convivientes en el domicilio, escolarización de los menores) se acreditan mediante informes emitidos por parte de los servicios sociales comunitarios (art. 16 del Decreto 2/1999).

Se hace necesaria una reflexión y actualización de la normativa que permita la intervención y coordinación entre otras Administraciones y su incorporación al catálogo de prestaciones básicas de los servicios sociales comunitarios, lo cual haría posible un mayor seguimiento y efectividad, teniendo en cuenta que el resto de medidas contempladas en el Programa (itinerarios profesionales, medidas educativas y de acceso a la vivienda) no han tenido el impulso necesario. La frustrada Ley de Inclusión Social de Andalucía (2007), propuesta para su debate parlamentario y suspendida sine die debido al contexto de crisis económica e incertidumbre política, incorporaba el concepto de renta básica ciudadana (con derechos y obligaciones), más amplio que el de renta mínima de inserción, y con un marcado carácter proactivo. Para ello, se contemplaban una serie de medidas, de índole administrativa, como la incorporación de las entidades locales a la estrategia para la inclusión social, otorgándoles potestades para su concesión, seguimiento y evaluación.

\subsection{El Programa de Suministros Mínimos Vitales y otras prestaciones de urgencia social}

En 2014, la Junta de Andalucía puso en marcha una serie de actuaciones para la mejora de la inclusión social y la cobertura de las necesidades de la ciudadanía, articulado a través del Decreto ley 8/2014, de 10 de junio, de Medidas Extraordinarias y Urgentes para la Inclusión Social a través del Empleo y el Fomento de la Solidaridad en Andalucía. En él se contemplaba el establecimiento de un Programa Extraordinario para Suministros Mínimos Vitales y Prestaciones de Urgencia Social, destinado a cubrir de forma ágil las situaciones de contingencia económica urgente de las necesidades básicas que no puedan ser atendidas por las personas que se encuentran en exclusión social.

El planteamiento establecía una serie de ayudas, gestionadas por los ayuntamientos de la comunidad autónoma de Andalucía, que, de manera complementaria a las ayudas de emergencia social referidas anteriormente, atendieran la cobertura de contingencias extraordinarias de las necesidades básicas de subsistencia, tanto por razones sobrevenidas como por falta continuada de recursos, de aquellas personas o unidades familiares que no puedan hacer frente a gastos específicos, y siempre con un carácter urgente, transitorio y puntual, con el fin de prevenir, evitar o paliar situaciones de exclusión social.

El programa establece dos líneas de subvenciones: una dirigida a suministros mínimos vitales; $y$ otra, a prestaciones de urgencia social. Para ambas se establecen una serie de gastos concretos:

- Ayudas para suministros mínimos vitales:

- Gastos de energía eléctrica producidos desde el momento en que no se puede hacer frente a la tarifa contratada, o bono social para el suministro eléctrico.

- Gastos derivados del suministro de agua producidos desde el momento en que no se puede hacer frente a la tarifa contratada.

- Otras prestaciones de urgencia social: los gastos necesarios para el disfrute y mantenimiento de la vivienda o alojamiento habitual (gastos de alquiler, siempre que su impago redunde en un desalojo, y alojamiento en situaciones de necesidad en albergues o establecimientos de hostelería), y gastos de reparaciones urgentes y básicas en las viviendas.

Una de las características de la gestión del programa es la libertad con la que cuentan las entidades locales para conceder las citadas ayudas, lo cual ha dado lugar a una importante diversidad administrativa en los procesos de valoración y adjudicación. La norma establece que los destinatarios serán aquellas personas o unidades familiares empadronadas en un municipio y que, a criterio de los servicios sociales comunitarios, carezcan de recursos económicos suficientes para cubrir las necesidades básicas y requieran una actuación inmediata, por lo que son los servicios sociales comunitarios los que fijan los requisitos de acceso y los criterios de valoración. En el Ayuntamiento de Vélez-Málaga, la concejalía competente en materia de servicios sociales comunitarios publica anualmente, desde 2014, unas bases reguladoras en las que se detalla el proceso de tramitación y los criterios de valoración para la concesión. Para 2015, el presupuesto municipal del citado programa ascendió a $26.000 €$, con un total de 210 unidades familiares beneficiarias.

\section{Discusión}

El estudio de las prestaciones económicas desde la perspectiva de la intervención en los servicios sociales comunitarios, aunque parcial, nos permite extrapolar diversas cuestiones de carácter general, que invitan a reflexionar. De esta forma, encontramos una multiplicidad de actores en el 'sistema' de protección económica para los ciudadanos. La tradición histórica ha condicionado nuestros sistemas de protección, de forma que existen 
múltiples intervinientes y entidades prestadoras de servicios. Si durante el franquismo, se plantea un sistema dual, que cubre, por un lado, a los trabajadores, y por otro, ofrece recursos benéficos y asistenciales para los excluidos del mercado de trabajo, con la llegada de la Constitución, el panorama no consigue cambiar de forma radical.

La indefinición, el reparto de competencias y la excesiva descentralización son resultado de la estanqueidad de los sistemas de protección, y de una pugna política por el monopolio de determinadas competencias, que en ocasiones confunden a la ciudadanía y dificultan la oferta de una respuesta integradora a los problemas sociales.

A la indefinición, el reparto de competencias y la excesiva descentralización ha conllevado la estanqueidad de sistemas de protección, y una competencia política por el monopolio de determinadas competencias, que en ocasiones confunden a la ciudadanía y dificultan la oferta de una respuesta integradora a los problemas sociales. De esta forma, han surgido en las comunidades autónomas una diversidad de programas de rentas mínimas, con intensidades de protección muy heterogéneas (Arriba, 2009), que aunque se configuran como un recurso de "última red de protección”, resultan interesantes, pues complementan los itinerarios de inserción social (Moreno Márquez, 2008). No obstante, es destacable cómo gran parte de estos programas, incluido el andaluz, se articulan en torno al concepto de concesión condicionada, estableciéndose objetivos que deben cumplir los beneficiarios, pero que rara son únicamente competencia propia (por ejemplo, encontrar un empleo, recibir determinada formación). Esto supone un importante peligro, pues la condicionalidad en el acceso a estos programas "abre la puerta a un mayor o menor grado de criminalización de la pobreza, la cual sirve de legitimador social al sistema político-económico actual” (Torre Millán, 2014: 101).

En este escenario de gran diversidad en la protección dentro de los territorios, se hace necesario incorporar a la agenda cuestiones como el papel de la Administración central en la normativa de servicios sociales, como instrumento para la vertebración del territorio, donde los programas de rentas mínimas o de mantenimiento de ingresos pueden tener un papel significativo. En esta línea, algunos autores plantean la idoneidad de solventar la disparidad de criterios y acción protectora mediante la "asunción por la Seguridad Social de esta nueva 'contingencia', aprobación de una ley de mínimos con carácter estatal o lanzamiento de un nuevo 'plan concertado' para las rentas mínimas” (Laparra, 2004: 70), como ya sucediera a finales de la década de los ochenta en el ámbito de los servicios sociales de atención primaria.

La dinámica social actual exige planteamientos legislativos amplios y fácilmente adaptables a las coyunturas del ciclo económico. Nuestro modelo de protección social, que podría encuadrarse en un modelo de economía capitalista de bienestar de tipo mediterráneo, trae aparejado una serie de condicionantes, a los que debemos sumar nuestro pasado más inmediato (dictadura franquista) y el modelo de configuración estatal surgido tras la Constitución. La inexistencia de pactos de Estado o de actores políticos decididos por un modelo concreto de economía de bienestar conlleva que la alternancia política (que en la actualidad se reduce a un bipartidismo de facto) suponga modificaciones legislativas profundas, que normalmente suponen una merma de derechos y el ejercicio de políticas clientelistas que favorecen a grupos de presión cercanos al poder del momento.

Nuestro Estado de bienestar, de reciente creación y construido sobre un modelo benéfico-asistencial, cuando en nuestro entorno ya se había planteado una crisis ideológica del sistema, hace que no se hayan previsto políticas orientadas a la integración social y a la prevención de la marginación y la desigualdad, tan necesarias para amortiguar las consecuencias de los ciclos económicos negativos. Así mismo, es importante también el hecho de que el sistema de servicios sociales "tradicionalmente ha sido el pilar del Estado de bienestar, más impreciso, más débil y más sensible a los cambios económicos, políticos y culturales, generando una necesidad de replanteamiento permanente" (Alguacil, 2012: 23), y que aunque ha tenido una etapa de consolidación y desarrollo, con la incorporación de prestaciones de derecho subjetivo, la crisis económica paralizó las reformas que había comenzado (Vilá, 2010).

En Andalucía, el reconocimiento legislativo a los servicios sociales no ha regulado los instrumentos de financiación de forma que facilitaran la independencia y suficiencia financiera que permitiera dotarse de un sistema para afrontar las situaciones de riesgo y exclusión social. La Ley 5/2010, de 11 de junio, de Autonomía Local de Andalucía, ha venido a completar la indefinición de la Ley de Régimen Local estatal (7/1985). El artículo 9.3 atribuye a los municipios la gestión de los servicios sociales comunitarios, conforme al Plan y Mapa Regional de Servicios Sociales de Andalucía, que incluye la gestión de los servicios sociales comunitarios. A pesar de este nuevo e innovador planteamiento y de una nueva norma reguladora de los mecanismos de financiación y de participación de los municipios en los tributos de la comunidad autónoma (Ley 6/2010), no se ha aprovechado la oportunidad para fijar niveles mínimos de gasto en servicios sociales que facilitaran la aplicación de lo establecido en las normas específicas, y posibilitaran una equidad y redistribución de la renta efectivos.

La nueva reforma del régimen local introducida por la Ley $27 / 2013$, de 27 de diciembre, a pesar de que los pronunciamientos del Tribunal Constitucional (sentencia 111/2016) han rebajado su tono, sitúan a los servicios sociales que se prestan desde la 
Administración local en una difícil tesitura, por cuanto los hace regresar hacia modelos de corte benéfico-asistencial (Uceda et al., 2014), y limitan e imponen tutelas a la autonomía local (Boix, 2014). Estas reformas intensifican los procesos de desarrollo de la acción privada en el ámbito de los servicios sociales que vienen ejecutándose desde su consolidación y expansión en la década de los ochenta y noventa, transfiriendo la responsabilidad al prestador (organizaciones no gubernamentales y empresas), mediante su financiación (Dominelli y Hoogvelt, 1996).

En el ámbito de las prestaciones del Sistema para la Autonomía Personal y Atención a la Dependencia, si bien el concurso de los servicios sociales comunitarios en Andalucía facilita la conexión de la prestación con el territorio y la realidad de las personas y familias, es una asignatura pendiente la mejora de los servicios de inspección y de seguimiento de las prestaciones. Éstas deben orientarse hacia lo preventivo y no únicamente hacia la fiscalización y el control de la condicionalidad, basado en un modelo de supervisión centrado en la colaboración positiva para la mejora de la atención de las personas en situación de dependencia (Siadeco Ikerketa Aplikatua, 2013), por lo que cabría esperar que esta función recalara, con los medios técnicos, económicos y humanos necesarios, en la esfera de los servicios sociales comunitarios.

Las prestaciones económicas de servicios sociales deben ir orientadas a la prevención y a la consecución de objetivos de reinserción social, hecho que resulta prácticamente imposible si los programas de apoyo económico continuado destinados al mantenimiento de ingresos se sitúan en niveles de la Administración más burocratizados y lejanos del ciudadano, donde es más complejo llevar a cabo una intervención profesional cercana y orientada a la coproducción del servicio, entre usuario y profesional. Por ello, se hace necesario encomendar la gestión de los programas de rentas mínimas, los más efectivos para favorecer la normalización e integración social, al nivel de atención primaria de los servicios sociales. En ese ámbito, el trabajo social como profesión de referencia en los servicios sociales comunitarios tiene un papel importante para provocar el cambio a través de una intervención e investigación social innovadora, planteando acciones que se dirijan hacia "el desarrollo de fórmulas creativas, retomar el compromiso social y político de la profesión, la deconstrucción de unos nuevos servicios sociales y el desarrollo del paradigma del trabajo social, a través de una intervención centrada en la persona y en su dimensión comunitaria" (Hernández-Echegaray, 2016: 64).

Como conclusión final, sería necesario abordar investigaciones que estudien el efecto de las prestaciones económicas de servicios sociales tanto en el aspecto cualitativo (consecución de objetivos de inserción social, mejora de la calidad de vida y salud de la población) como en el plano económico (efectos sobre el consumo y la mejora de la demanda interna, sobre el mercado de vivienda e impagos de alquileres e hipotecas), investigaciones que podrían abarcar también los programas de mantenimiento de ingresos o rentas mínimas autonómicas, como mecanismos para evitar la exclusión social. Así mismo, se deben promover planteamientos políticos y legislativos que incidan en la estructuralidad del problema y que no configuren a los servicios sociales como un instrumento para mantener o contener (y no superar) las situaciones de desigualdad. Para ello, se debe evitar el énfasis en aspectos cuantitativos (monetarios), frente a cuestiones cualitativas, poniendo en valor los recursos humanos (las personas, tanto beneficiarias como profesionales) y la orientación hacia la excelencia como únicos métodos para la protección social integral y la consecución de objetivos de bienestar social. 


\section{Referencias bibliográficas}

ALGUACIL, J. (2012): “La quiebra del incompleto sistema de Servicios Sociales en España", Cuadernos de Trabajo Social, vol. 25, $\mathrm{n}$ - 1, págs. 63-74 ['https://doi.org/10.5209/rev_CUTS.2012.v25. n1.38434)].

ANDALUCÍA (2014): “Decreto ley 8/2014, de 10 de junio, de medidas extraordinarias y urgentes para la inclusión social a través del empleo y el fomento de la solidaridad en Andalucía”, Boletín Oficial de la Junta de Andalucía, no 113, 13-6-2014, págs. 54-124 [khttp://www. juntadeandalucia.es/boja/2014/113/4>].

- (2013): “Decreto ley 7/2013, de 30 de abril, de medidas extraordinarias y urgentes para la lucha contra la exclusión social en Andalucía", Boletín Oficial de la Junta de Andalucía, no 85, 3-5-2013, págs. 27-88 [<http://www. juntadeandalucia.es/boja/2013/85/BOJA13085-00062-7379-01_00026320.pdf>].

- (2013): “Orden de 10 de octubre de 2013, por la que se regulan las Ayudas Económicas Familiares y su gestión mediante la cooperación entre la Junta de Andalucía y las Entidades Locales", Boletín Oficial de la Junta de Andalucía, no 204, 16-10-2013, págs. 8-21 [khttp://www. juntadeandalucia.es/boja/2013/204/1>].

- (2010): “Ley 5/2010, de 11 de junio, de Autonomía Local de Andalucía", Boletín Oficial de la Junta de Andalucía, no 122, 23-6-2010, págs. 6-34 [<http://www.juntadeandalucia.es/ boja/2010/122/11].

- (2010): “Ley 6/2010, de 11 de junio, reguladora de la participación de las entidades locales en los tributos de la Comunidad Autónoma de Andalucía", Boletín Oficial de la Junta de Andalucía, no 123, 24-6-2010, págs. 8-35 [<http://www.juntadeandalucia.es/ boja/2010/123/1>].
- (2007): "Decreto 168/2007, de 12 de junio, por el que se regula el procedimiento para el reconocimiento de la situación de dependencia y del derecho a las prestaciones del Sistema para la Autonomía y Atención a la Dependencia, así como los órganos competentes para su valoración", Boletín Oficial de la Junta de Andalucía, no 119, 18-6-2007, págs. 38-42 [rhttp://www. juntadeandalucia.es/boja/2007/119/d3.pdfs].

- (1999): “Decreto 2/1999, de 12 de enero, por el que se regula la creación del Programa de Solidaridad de los Andaluces para la Erradicación de la Marginación y la Desigualdad", Boletín Oficial de la Junta de Andalucía, no 16, 6-2-1999, págs. 1.531-1.536 [rhttp://www. juntadeandalucia.es/boja/1999/16/d8.pdf〉].

- (1998): “Orden de 13 abril 1998, por la que se regulan las Ayudas Económicas Familiares y su gestión mediante la cooperación entre la Junta de Andalucía y las Corporaciones Locales", Boletín Oficial de la Junta de Andalucía, no 49, 2-5-1998 [rhttp://www.juntadeandalucia.es/ boja/1998/49/3>].

- (1992): "Decreto 11/1992, de 28 de enero, sobre naturaleza y prestaciones de los Servicios Sociales Comunitarios", Boletín Oficial de la Junta de Andalucía, no 17, 25-2-1992 ['http:// www.juntadeandalucia.es/boja/1992/17/9>].

- (1992): “Orden de 20 de abril de 1992, por la que se establecen las normas que han de regir entre la Junta de Andalucía y las Corporaciones Locales de su territorio en materia de Ayudas Económicas Familiares para Atención al Niño, como prestación básica de los Servicios Sociales Comunitarios", Boletín Oficial de la Junta de Andalucía, no 36, 30-4-1992, págs. 2.436-2.438 [<http://www. juntadeandalucia.es/boja/1992/36/d22.pdfs]. 
- (1988): "Ley 2/1988, de 4 de abril, de Servicios Sociales de Andalucía”, Boletín Oficial de la Junta de Andalucía, no 29, 12-4-1988, págs. 1.3231.328 [rhttp://www.juntadeandalucia.es/ boja/1992/17/9>].

- (1986): “Decreto 49/1986, de 5 de marzo, para la creación de los Servicios Sociales Comunitarios de Andalucía”, Boletín Oficial de la Junta de Andalucía, no 32, 15-4-1986 [<http://www. juntadeandalucia.es/boja/1986/32/1>].

ARRIBA, A. (2009): “Rentas mínimas de inserción de las comunidades autónomas: una visión conjunta de su evolución y alcance", Gestión y Análisis de Políticas Públicas, $n^{\circ}$ 2, págs. 81-100.

AUSTIN, D. (2002): Human Services Management: Organizational Leadership in Social Work Practice, Nueva York, Columbia University Press.

AYUNTAMIENTO DE MEDINA DEL CAMPO (2004): “Plan Estratégico de Servicios Sociales del municipio de Medina del Campo", Ayuntamiento de Medina del Campo [rhttp://www. ayto-medinadelcampo.es/documentos/ Servicios\%20Sociales/PLAN\%20MPAL.\%20 SERVICIOS\%20SOCIALES.pdf)].

AYUNTAMIENTO DE VÉLEZ-MÁLAGA (2016): “Reglamento de la Prestación de Ayudas de Emergencia Social de los Servicios Sociales Comunitarios del Ayuntamiento de Vélez-Málaga”, Boletín Oficial de la Provincia de Málaga, ํㅜ101, 30-5-2016, págs. 24-28.

- (2015a): "Impulsando Vélez-Málaga. Plan Estratégico Vélez-Málaga 2015-2025”, Ayuntamiento de Vélez-Málaga [shttp://www.velezmalaga.es/ contenido/datos/presidencia/documentos/4.Plan-estrategico-final-1PARA-WEBAYUNTAMIENTO-10092015-SBOyk5.pdf>].

- (2015b): "Reglamento de Prestación de las Ayudas Económicas Familiares de los Servicios Sociales Comunitarios del Ayuntamiento de VélezMálaga”, Boletín Oficial de la Provincia de Málaga, no108, 8-6-2015, págs. 29-32.

BOIX, A. (2014): "Sentido y orientación de la Ley 27/2013 de racionalización y sostenibilidad de la Administración local: autonomía local, recentralización y provisión de servicios públicos locales", Revista de Estudios de la Administración Local y Autonómica, Nueva Época, $\mathrm{n}$ - 2 [rhttp://revistasonline.inap.es/ index.php?journal $=$ REALA $\&$ page $=$ article $\& o p=v i$ ew\&path $\% 5 B \% 5 D=10199>]$.

CERDEIRA, I. (1987): "Los servicios sociales del franquismo a la Constitución”, Cuadernos de Trabajo Social, noo, págs. 135-158 [khttp://revistas. ucm.es/index.php/CUTS/article/view/ CUTS8787110135A>].

CERVERA, M. et al. (2012): Informe final del grupo de expertos para la evaluación del desarrollo y efectiva aplicación de la Ley 39/2006, Madrid, Imserso [/http://hdl.handle.net/11181/3379〉].

CORDERO MARTIN, G. (2006): "Los servicios sociales y la organización del territorio", Acciones $e$ Investigaciones Sociales, $\mathrm{n}$ - 1 (extra), pág. 444 [rhttps://papiro.unizar.es/ojs/index.php/ais/ article/view/458>].
DOMINELLI, L.; y HOOGVELT, A. (1996): “Globalization and the technocratization of social work", Critical Social Policy, vol. 16, n- 47, págs. 45-62 [<https://doi.org/10.1177/026101839601604 703)].

ESPAÑA (2013): “Ley 27/2013, de 27 de diciembre, de Racionalización y Sostenibilidad de la Administración Local”, Boletín Oficial del Estado, n-0 312, 30-12-2013, págs. 106.430106.473 [ [https://www.boe.es/diario_boe/txt. php?id=BOE-A-2013-13756)].

- (2006): “Ley 39/2006, de 14 de diciembre, de Promoción de la Autonomía Personal y Atención a las Personas en Situación de Dependencia”, Boletín Oficial del Estado, no 299, 15-12-2016, págs. 44.142-44.156 [<https://www.boe.es/ buscar/doc.php?id=BOE-A-2006-21990>].

- (2003): "Ley 38/2003, de 17 de noviembre, General de Subvenciones", Boletín Oficial del Estado, n- 276, 18-11-2003, págs. 40.50540.532 [ [http://www.boe.es/buscar/doc. php?id=BOE-A-2003-20977/].

- (1985) "Ley 7/1985, de 2 de abril, Reguladora de las Bases del Régimen Local", Boletín Oficial del Estado, no 80, 3-4-1985, págs. 8.9458.964 [/https://www.boe.es/diario_boe/txt. php?id=BOE-A-1985-5392>].

- (1978): “Constitución española”, Boletín Oficial del Estado, n- 311, 29-12-1978, págs. 29.31329.424 [shttps://www.boe.es/buscar/doc. php?id=BOE-A-1978-31229)].

- (1959): "Decreto ley 10/1959, de 21 de julio, de ordenación económica", Boletín Oficial del Estado, no 174, 22-7-1959, págs. 10.00510.007 [/http://www.boe.es/datos/pdfs/ BOE/1959/174/A10005-10007.pdf)].

FUNDACIÓN FOESSA (1966): Informe sociológico sobre la situación social de España, Madrid, Fundación Foessa [rhttp://www.caritas.es/publicaciones compra.aspx $? \mathbf{I d}=3764 \&$ Idioma $=1 \&$ Diocesis $=1\rangle]$.

GIMÉNEZ BERTOMEU, V. M.; y DOMÉNECH LÓPEZ, Y. (2012): "Expertos por la experiencia y expertos por la profesión. Visiones sobre la práctica profesional en los Servicios Sociales de Atención Primaria”, Cuadernos de Trabajo Social, vol. 25, no 2, págs. 439-449 [khttps:// doi.org/10.5209/rev_CUTS.2012.v25. n2.39628>].

GUZMÁN, F.; MOSCOSO, M.; y TOBOSO, M. (2010): “Por qué la Ley de Dependencia no constituye un instrumento para la promoción de la autonomía personal”, Zerbitzuan, no 48 , págs. 43-56 [<http://www.zerbitzuan.net/documentos/ zerbitzuan/Ley de dependencia no constituye un instrumento.pdf`].

HERNÁNDEZ-ECHEGARAY, A. (2016): “Tendencias del Trabajo Social en el ámbito de los Servicios Sociales desde la perspectiva profesional. Estudio Delphi”, Comunitania. Revista Internacional de Trabajo Social y Ciencias Sociales, $\mathrm{n}-12$, págs. 45-68 [<http://www.comunitania.com/ arantxa-hernandez-echegaray-tendencias-deltrabajo-social-en-el-ambito-de-los-serviciossociales-desde-la-perspectiva-profesionalestudio-delphi/>]. 
HERRERA GÓMEZ, M.; y CASTÓN, P. (2003): Las políticas sociales en las sociedades complejas, Barcelona, Ariel.

INSTITUTO DE ESTADÍSTICA Y CARTOGRAFÍA DE ANDALUCÍA (2015): "Velez-Málaga (Málaga)", en Andalucía, pueblo a pueblo (base de datos) [rhttp://www.juntadeandalucia.es/ institutodeestadisticaycartografia/sima/ nucleos/consulta.php?CodMuni=29094\#>, consultado el 27-7-2016].

INSTITUTO NACIONAL DE ESTADÍSTICA (2015): “VélezMálaga”, en Cifras oficiales de población resultantes de la revisión del Padrón municipal a 1 de enero (base de datos) [/http://www.ine. es/jaxiT3/Datos.htm?t=2882〉].

JUNTA DE ANDALUCÍA. CONSEJERÍA DE IGUALDAD, SALUD Y POLIITICAS SOCIALES (2007): "Anteproyecto de Ley de Inclusión Social en Andalucía” [<http://www.juntadeandalucia.es/ igualdadybienestarsocialopencms/system/ bodies/Programas_Solidaridad/Legislacion/ R20071102_borrado/LISA_30_de_octubre. pdf>].

LAPARRA, M. (2004): “La travesía del desierto de las rentas mínimas en España”, Documentación Social, n- 135 , págs. 57-76.

LEE, A. V.; VARGO, J.; y SEVILLE, E. (2013): “Developing a tool to measure and compare organizations' resilience", Natural Hazards Review, vol. 14, no 1, págs. 29-41 [khttps://doi.org/10.1061/ (asce)nh.1527-6996.0000075’].

LENGNICK-HALL, C. A.; BECK, T. E.; y LENGNICK-HALL, M. L. (2011): “Developing a capacity for organizational resilience through strategic human resource management", Human Resource Management Review, vol. 21, no 3 , págs. 243-255 [<https://doi.org/10.1016/j. hrmr.2010.07.001)].

LÓPEZ CASANOVAS, G.; y DEL POZO RUBIO, R. (2010): La protección social de los problemas de dependencia en España, serie Documentos de Trabajo CRES; Fundación Caser, nํㅜ 1, Barcelona, Fundación Caser-Universidad Pompeu Fabra [rhttps://www.upf.edu/cres/_pdf/wp1_caser_ cres.pdf $\rangle$.

LÓPEZ-PÉREZ, M. (2012): “Prestación económica de asistencia personal: asignatura pendiente de la Ley 39/2006, de 14 de diciembre", Portularia, vol. 12, nํe extra, págs. 111-120 [rhttp://rabida.uhu.es/dspace/bitstream/ handle/10272/5942/Prestacion_economica_ de_asistencia_personal.pdf $\rangle$ ].

MORENO MÁRQUEZ, G. (2008): “La reformulación del Estado del bienestar: el workfare, las políticas activas de empleo y las rentas mínimas", Zerbitzuan, no 43, págs. 143-154 [<http://www.zerbitzuan. net/documentos/zerbitzuan/Reformulaicon del Estado del bienestar.pdf $>$ ].

NAVARRA (1983): “Ley Foral 14/1983, de 30 de marzo, de Servicios Sociales”, Boletín Oficial de Navarra, no 44, 8-4-1983 [<http://www.lexnavarra. navarra.es/detalle.asp? $r=10658>]$.

PACHECO-MANGAS, J.; y HERNÁNDEZ-ECHEGARAY, A. (2014): "Los sistemas de rentas mínimas: protección social, ciudadanía y clientelismo político. Un análisis comparado entre Andalucía y Castilla y León”, Zerbitzuan, no56, págs. 101-114 [<https://doi.org/10.5569/1134-7147.56.07)].

PAÍS VASCO (1982): “Ley 6/1982, de 20 de mayo, sobre Servicios Sociales", Boletín Oficial del País Vasco, no 71 , 2-6-1982, págs. 1.263-1.273 [rhttps://www.euskadi.eus/y22-bopv/es/ bopv2/datos/1982/06/8200685a.shtml)].

PEIRÓ, J. M. (1990): Organizaciones: nuevas perspectivas psicosociológicas, Barcelona, PPU.

RODRÍGUEZ CABRERO, G. (2007): “La protección social de la dependencia en España. Un modelo 'sui generis' de desarrollo de los derechos sociales”, Política y Sociedad, vol. 44, ํㅜ 2, págs. $69-85$ [shttp://revistas.ucm.es/index. $\mathrm{php/POSO/article/view/23399>].}$

SCHEIN, E. A. (1985): Organizational Culture and Leadership, San Francisco, Jossey-Bass.

SIADECO IKERKETA APLIKATUA (2013): “Las prestaciones económicas de dependencia en Gipuzkoa: concurrencia, impacto y supervisión", Zerbitzuan, nํ5 54, págs. 47-66 ['https://doi. org/10.5569/1134-7147.54.03)].

TORRE MILLÁN, I. (2014): "Política vasca de garantía de ingresos: los riesgos de criminalización de la pobreza de un modelo condicional", Zerbitzuan, n-0 57, págs. 91-102 [<https://doi. org/10.5569/1134-7147-57.05'].

TRIBUNAL CONSTITUCIONAL. PLENO (2016): “Recurso de inconstitucionalidad 1959/2014. Sentencia número 111/2016, de 9 de junio”, Boletín Oficial del Estado, ํำ170, 15-7-2016, págs. 50.172-50.220 [<https://www.boe.es/boe/ dias/2016/07/15/pdfs/BOE-A-2016-6839.pdf)].

UCEDA, F. X. et al. (2014): "La pérdida de garantía en los Servicios Sociales Comunitarios: la reforma local”, Azarbe. Revista Internacional de Trabajo Social y Bienestar, n으, 3, págs. 247-251 [rhttp:// revistas.um.es/azarbe/article/view/198711)].

UCEDA, F. X. et al. (2013): “Els Serveis Socials Municipals en risc de desaparició", TSNova. Trabajo Social y Servicios Sociales, $\mathrm{n}-7$, págs. $73-86$ [ [rhttp:// roderic.uv.es/handle/10550/51822>].

VILÀ, A. (2010): "Los cambios legislativos en materia de Servicios Sociales (2000-2009)”, en CASADO, D. (coord.), Leyes de Servicios Sociales del siglo XXI, págs. 17-48, Madrid, Fundación Foessa.

VILLALOBOS, J. (2008): “Impacto de la Ley de Promoción de la Autonomía Personal y Atención a Personas en Situación de Dependencia en los Servicios Sociales Comunitarios", Documentos de Trabajo Social, nํ43-44, págs. 9-28. 